\title{
Structure and wear resistance of Ti-TiC-TiB layers obtained by non-vacuum electron beam cladding
}

\author{
Olga Lenivtseva ${ }^{1, *}$, Lyubov Chuchkova ${ }^{1}$, and Dina Krivezhenko ${ }^{1}$ \\ ${ }^{1}$ Department of Materials Science in Mechanical Engineering, Novosibirsk State Technical University, 630073, K. Marks av., \\ 20, Novosibirsk, Russia
}

\begin{abstract}
In this study structure and tribotechnical properties of cp-titanium after non-vacuum electron beam cladding of powder mixture containing boron carbide were investigated. Structural investigations were carried out using optical and scanning electron microscopy and X-ray analysis. The thickness of cladded layers was $1.3 \ldots 2.5 \mathrm{~mm}$. The beam moving speed was not influence the phase composition of coatings. The main phases of the surface layers were $\alpha$ - titanium $\left(\alpha^{\prime}-\right.$ titanium), titanium carbide $\mathrm{TiC}$ and titanium boride $\mathrm{TiB}$. It was determined that the average value of microhardness of the samples formed with the speed $25 \mathrm{~mm} / \mathrm{s}$ was three times higher in comparison with substrate metal. A decrease in the beam moving speed led to an increase in the heat input per unit area and was accompanied by a reduction in the coating microhardness. To evaluate the wear resistance, friction test of the obtained materials against fixed abrasive particles was performed. The maximum relative wear resistance was exhibited by the coatings after cladding of 20 wt. \% boron carbide and $30 \mathrm{wt} . \%$ titanium with the beam moving speed of $25 \mathrm{~mm} / \mathrm{s}$. Their wear resistance was 1.53 times higher as compared to cp-titanium.
\end{abstract}

\section{Introduction}

Titanium is a unique metal. At the present time, titanium alloys are widely used in aircraft industry, shipbuilding, mechanical engineering, automobile production, rocket engineering, oil and gas industry and medicine. Due to its physical and mechanical properties, titanium and its alloys are universal structural materials [1, 2]. High corrosion resistance, strength, low weight and durability provide titanium products with undeniable advantages over the similar products made from other metal alloys.

However, titanium alloys have several significant disadvantages. These are its low tribotechnical properties. Thus, the rate of abrasive wear of titanium alloys is 7 times higher than the rate of wear of carbon steel 1080 [3]. In contact with other structural materials, titanium alloys tend to severe abrasive and adhesive wear [3-5].

Recently, a lot of studies have been devoted to improving the tribotechnical properties of titanium alloys by the formation of composite coatings on their surface (TMC - titanium matrix composites) using laser and electron beam technologies [6-14]. Particles of carbides, borides, and silicides of metals act as hardening components in these materials. In addition, the base metal acts as a binder for ceramic particles, providing a good metallurgical bond.

The first researches that dedicated to the applying of lasers for surface hardening of materials appeared in $1970[15,16]$. In these studies great attention was paid to the processes of melting and crystallization of the materials, which have a significant effect on the structural-phase state and properties of the layers. The preparation of reinforcing particles in the cladded layers is possible with several approaches: the introduction of hardening particles directly into the melting metal [8-11] or the simultaneous melting of the surface layer of substrate material and the powder mixtures. When applying the first approach, the particles do not have enough time for dissolving in the base material and retain their original shape and size.

Feeding of the powders into the molten bath occurs in a stream of inert gas or is dosed through a hopper. When applying the second approach, the morphology of the particles slightly affects the initial composition of the powder mixtures, due to their complete dissolving in the melt bath during the treatment [17-21]. Both approaches increase in the stability and wear resistance of the titanium surface layers.

In this study, the method of non-vacuum electron beam cladding of boron carbide and titanium powder mixture on titanium plates (VT1-0 alloy) was used to synthesize hardening titanium carbide and titanium boride particles. This technology is characterized by high performance and allows forming the coatings with a thickness of 1 to $3 \mathrm{~mm}[14,22-28]$. The microstructure, phase composition and tribotechnical tests of the coatings were investigated.

\section{Materials and methods}

Cp-titanium plates with dimensions of 100x50x12 mm were used as substrates. A powder mixture, that was

\footnotetext{
* Corresponding author: lenivtseva_olga@mail.ru
} 
used to synthesize hardening particles in the surface layers of titanium, consisted of $20 \mathrm{wt}$. \% of boron carbide (average particle size $20 \mu \mathrm{m}$ ) and 30 wt. titanium (average particle size $100 \mu \mathrm{m}$ ). To provide protection of the melt from air oxygen 40 wt. $\%$ of $\mathrm{CaF}_{2}$ and 10 wt. $\%$ of $\mathrm{LiF}$ were added to the powder mixture. The electron beam treatment of the samples was carried out an ELV-6 electron accelerator produced by the Budker Institute of Nuclear Physics (Novosibirsk). The scheme of the electron accelerator is represented in [29, 30]. Table 1 shows the technological parameters of the process.

Table 1. Technological processing parameters.

\begin{tabular}{|l|l|}
\hline Electron energy & $\mathrm{E}=1.4 \mathrm{MeV}$ \\
\hline Beam current from the outlet & $\mathrm{I}=28 \mathrm{~mA}$ \\
\hline $\begin{array}{l}\text { Distance fram } \\
\text { window to the workpiece }\end{array}$ & $\mathrm{dm}$ \\
\hline $\begin{array}{l}\text { Beam size (the Gaussian } \\
\text { diameter) }\end{array}$ & $\mathrm{d} \mathrm{mm}$ \\
\hline Scanning frequency & $\mathrm{l}=50 \mathrm{~Hz}$ \\
\hline Scanning width & $\begin{array}{l}\mathrm{V}_{1}=15, \quad \mathrm{~V}_{2}=20 \text { and } \\
\mathrm{V}_{3}=25 \mathrm{~mm} / \mathrm{s}\end{array}$ \\
\hline Beam moving speed
\end{tabular}

Metallographic analysis was carried out using a Carl Zeiss Axio Observer Z1m optical microscope and a Carl Zeiss EVO 50 XVP scanning electron microscope. Evaluation of the hardening particles sizes was carried out on micrographs taken from non-etched polished samples using the ImageJ program.

The phase analysis of the coatings was performed on $\theta-\theta$ ARL X'TRA diffractometer using $\mathrm{Cu} \mathrm{K} \alpha$ radiation. Diffraction patterns were registered in a stepwise mode with a step $0.05^{\circ}$. The dwell time was $12 \mathrm{~s}$. During the X-ray diffraction study a pinhole collimator was used. Identification of phases was performed using PDF-4 database.

The Wolpert Group 402 MVD tester was used to measure the distribution of microhardness over the depth of the cladded layers. Measurements were performed on cross-sections in the direction from the surface of the cladded layer towards the substrate. The indenter load was $0.98 \mathrm{~N}$.

The evaluation of the wear resistance level of the obtained materials was carried out under friction test against fixed abrasive particles in accordance with the Russian standard GOST 17367-71 (the closest analogue is the ASTM G132-96 standard) [31]. The testing scheme is presented in [30]. The wear resistance was estimated based on the ratio of the linear dimension loss of the standard sample to the tested sample. Titanium alloy VT1-0 was used as a standard sample.

\section{Results}

During this study, several microstructural zones of the obtained materials were revealed: the zone of the melted material (cladded layer), the heat affected zone (HAZ), and the zone with the unaltered titanium structure. Cladding of boron carbide and titanium carbide powders at the beam moving speed $\mathrm{V}_{1}=15 \mathrm{~mm} / \mathrm{s}$ leads to the formation of the layers with a thickness of $2.5 \mathrm{~mm}$ (Fig.
1 a). An increase in beam moving speed is accompanied by a decrease in the coatings thickness from 1.7 to 1.3 $\mathrm{mm}$ at the speed of $\mathrm{V}_{2}=20$ and $\mathrm{V}_{3}=25 \mathrm{~mm} / \mathrm{s}$, respectively (Fig. $1 \mathrm{~b}, \mathrm{c}$ ). This effect is due to the change of the heat input per unit area. According to [28], taking into account the reflection of electrons from the surface, the input energy per unit area is 2.89, 3.61 and $4.81 \mathrm{~kJ} / \mathrm{cm}^{2}$ at the speed of 25,20 and $15 \mathrm{~mm} / \mathrm{s}$, respectively.

It should be noted that all layers have high quality. However, non-dissolved particles of boron carbide with the size $\sim 15 \mu \mathrm{m}$ were determined in the structure of the coatings. Mainly they are located near the heat affected zone. Reduction of the beam moving speed to $15 \mathrm{~mm} / \mathrm{s}$ is accompanied by almost complete dissolution of boron carbide particles. In addition, cracks were revealed in the cladded layer of sample $2\left(\mathrm{~V}_{2}=20 \mathrm{~mm} / \mathrm{s}\right)$ (Fig. $\left.1 \mathrm{~b}\right)$.

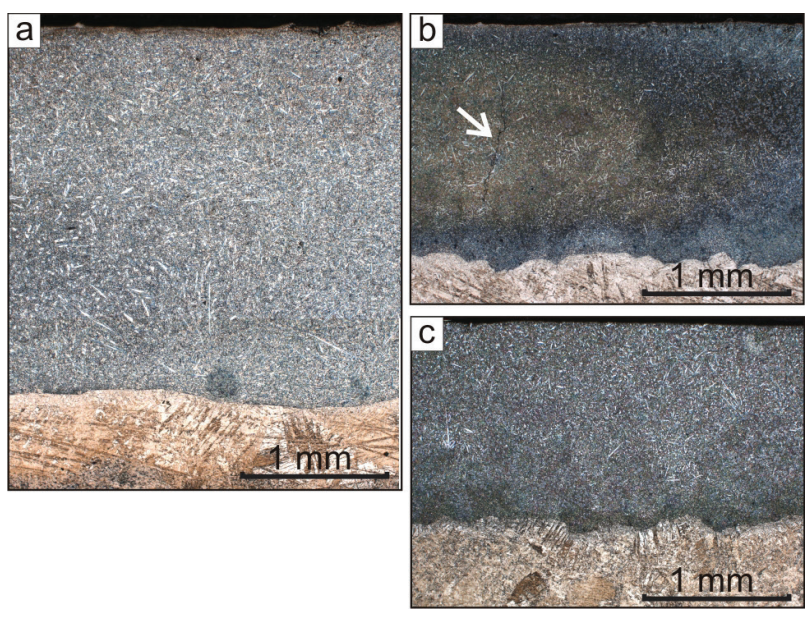

Fig. 1. The cross-section of the layers obtained by non-vacuum electron beam cladding of boron carbide and titanium at a beam moving speed $\mathrm{V}_{1}=15$ (a), $\mathrm{V}_{2}=20$ (b), and $\mathrm{V}_{3}=25 \mathrm{~mm} / \mathrm{s}$ (c).

Figure 2 shows a typical X-ray diffraction pattern taken from the surface of the cladded layer. An analysis of the obtained data showed that a change of the beam moving speed was not affected the phase composition of cladded layers. According to the obtained data three phases were detected in the cladded layers: $\alpha$-titanium ( $\alpha$ - titanium) with a hexagonal lattice, titanium carbide with a cubic lattice, and titanium monoboride with an orthorhombic lattice. No reflexes of boron carbide phase on the X-ray diffraction patterns were found. The displacement of the titanium carbide peaks towards large angles indicates a change in the lattice parameters. Considering the wide range of homogeneity of this phase, it can be assumed that nonstoichiometric titanium carbide observed in these coatings has $\mathrm{TiCx}$ formula, where $\mathrm{x}<1$.

The final structure of the cladded layers depends on the cooling conditions of the material during crystallization. Considering different speeds of heating and cooling of zones located from the surface, a gradient structure formed during electron beam cladding. The greatest supercoiling degree was observed at the boundary «molten bath - base metal». Consequently, the layers obtained at higher speed $\left(\mathrm{V}_{3}=25 \mathrm{~mm} / \mathrm{s}\right)$ had the 
higher supercoiling degree, the size of structural components is lower (Fig. 1). The average size of titanium boride crystals was equaled to $65 . . .70 \mu \mathrm{m}$. The maximum length of $\mathrm{TiB}$ was about $260 \mu \mathrm{m}$. Decreasing the beam moving speed to $\mathrm{V}_{1}=15 \mathrm{~mm} / \mathrm{s}$ is accompanied by an increase in boride crystals dimensions to $510 \mu \mathrm{m}$.

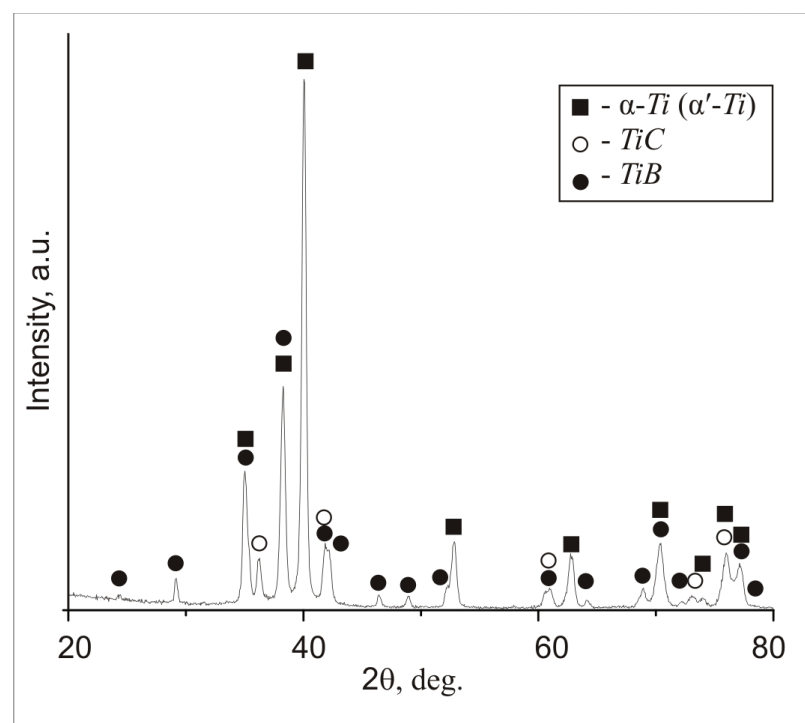

Fig. 2. Diffraction patterns of the cladded layers.

The mechanism of titanium boride crystals growing is determined by the type of their crystal lattice. X-ray diffraction analysis showed that titanium monoboride has an orthorhombic lattice (structural type $\mathrm{FeB}$ ). Titanium boride mainly grows in the longitudinal direction and in the plane of the cross-section it has the shape of hollow hexagonal prisms cut at different angles or fine needle-like crystals (Fig. 3). Figure 3a shows that due to a lack of boron atoms and a high cooling rate, the shape of titanium boride crystals was not regular. An interesting feature is the growing of titanium carbide dendrites on the faces of boride crystals (Fig. 3b).

Changing of microhardness over the depth of the cladded layers indicates the formation of gradient structure after electron beam cladding (Fig. 4). The average microhardness level rises from 452 to $503 \mathrm{HV}$ with an increase in beam moving speed from 15 to 25 $\mathrm{mm} / \mathrm{s}$, respectively. The peaks of the microhardness are due to indenting the hard particles (TiB and TiC), which hardness is much higher than the hardness of the substrate.

In the tests against fixed abrasive particles, the wear resistance of cp-titanium was chosen as a reference value. Analysis of tribological test results indicates that the significant differences in the relative wear resistance of the investigated layers were not observed. In the conditions of friction test against fixed abrasive particles the cladded layers demonstrated higher wear resistance $(1.42 \ldots 1.56)$ relative to the $\mathrm{cp}$-titanium samples.
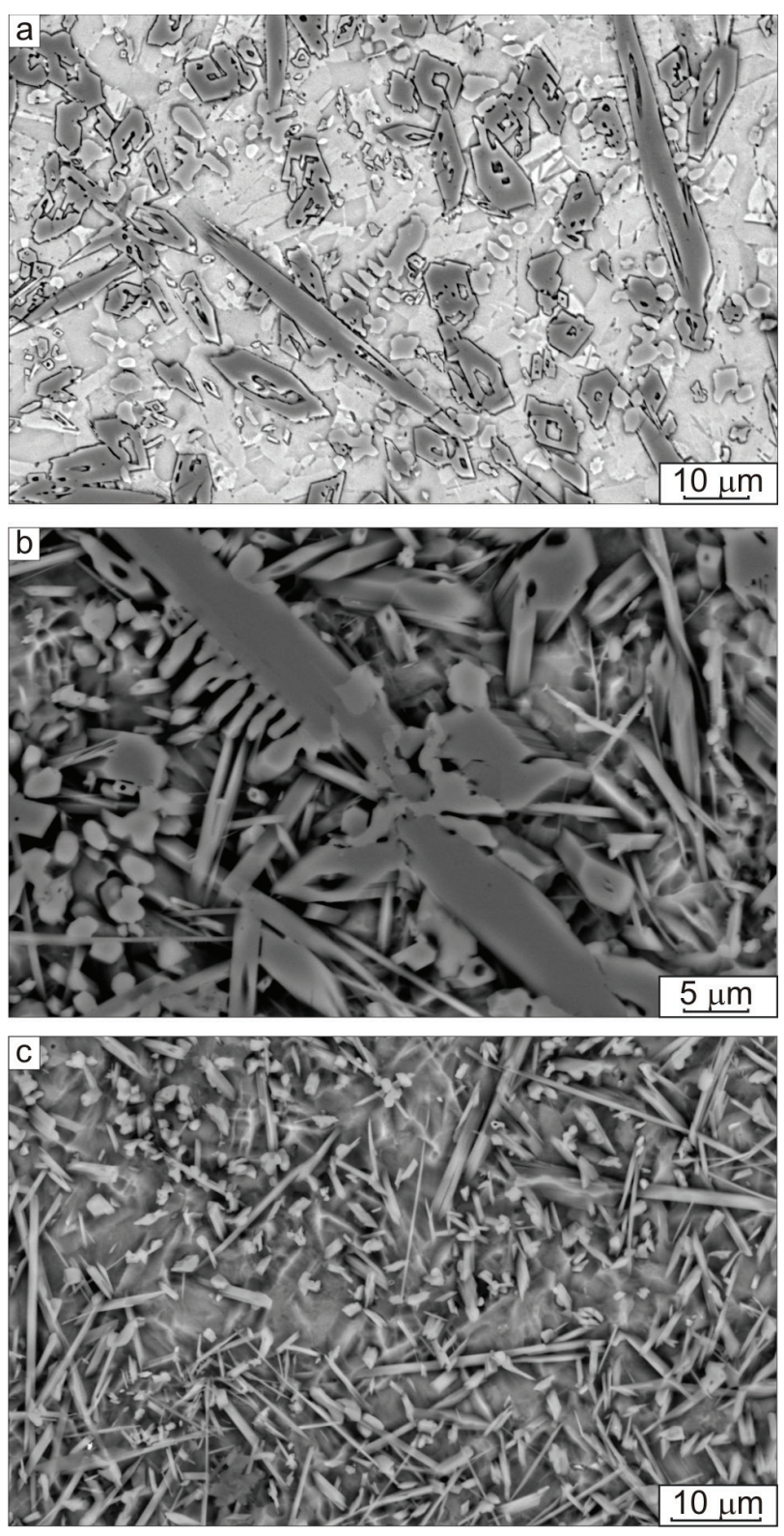

Fig. 3. The structure of cladded layers obtained by scanning electron microscopy.

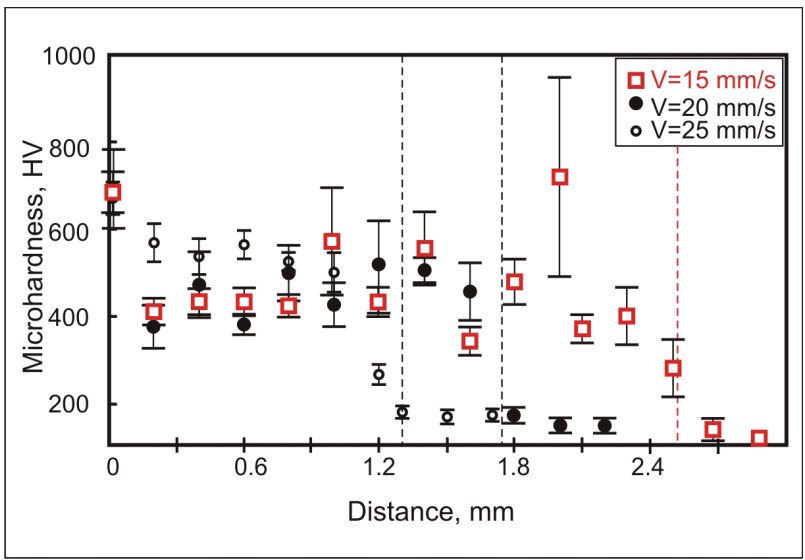

Fig. 4. Distribution of microhardness over the depth of cladded layers. 


\section{Conclusions}

Non-vacuum electron beam cladding of powder mixtures containing boron carbide on cp-titanium plates provides the formation of qualitative hardening layers with a thickness of $1.3 \ldots 2.5 \mathrm{~mm}$. Changing the beam moving speed affects not only the thickness of the layers, but also the size of the hardening particles ( $\mathrm{TiC}$ and $\mathrm{TiB}$ ) and the properties of obtained coatings.

Cladding with a beam moving speed of $25 \mathrm{~mm} / \mathrm{s}$ allows increasing the average microhardness level up to $503 \mathrm{HV}$, which is about 3 times higher than the hardness of the substrate. Surface hardening of cp-titanium with carbides and borides of titanium improves resistance of materials under abrasive wear conditions. Relative wear resistance of the obtained layers under an impact of fixed abrasive particles is 1.56 times higher compared to $\mathrm{cp}$ titanium.

The reported study was funded by RFBR, according to the research project No. 16-33-60066 mol_a_dk.

\section{References}

1. G. Lütjering, J. Williams, Titanium (Springer Berlin Heidelberg, Berlin, 2007)

2. C. Leyens, M. Peters, Titanium and Titanium Alloys: Fundamentals and Applications (WileyVCH Verlag GmbH \& Co. KGaA, Weinheim, 2005)

3. H. Dong, Surface Engineering of Light Alloys (Woodhead Publishing, 2010)

4. P.D. Miller, J.W. Holladay, Wear, 2, 133-140 (1958)

5. E. Rabinowicz, Metal Progress, 65, 107-110 (1954)

6. R. Yazdi, S.F. Kashani-Bozorg, Mater. Chem. Phys. 152, 147-157 (2015)

7. W.F. Wang, L.S. Jin, J.G. Yang, F.J. Sun, Surf. Coat. Technol. 236, 45-51 (2013)

8. V. Amigó, J.J. Candel, P. Franconetti, Materials Science Forum, 299-304 (2012)

9. J.J. Candel, V. Amigó, J.A. Ramos, D. Busquets, Surf. Coat. Technol. 204, 3161-3166 (2010)

10. Y. Chen, D. Liu, F. Li, L. Li, Surf. Coat. Technol. 202, 4780-4787 (2008)

11. V. Ocelík, D. Matthews, J.T.M. De Hosson, Surf. Coat. Technol. 197, 303-315 (2005)

12. F. Weng, C. Chen, H. Yu, Mater Design, 58, 412425 (2014)

13. O. Lenivtseva, E. Golovin, V. Samoylenko, D. Mul, D. Golovin, Advanced Materials Research, 1040, 784-789 (2014)

14. O.G. Lenivtseva, N.S. Belousova, E.A. Lozhkina, T.A. Zimoglyadova, V.V. Samoylenko, L.V. Chuchkova, IOP Conference Series: Materials Science and Engineering, 156, Art. 0120212016 (2016)

15. J.D. Ayers, R.T. Schaffer, Metal, 33, 19-23 (1981)
16. C.W. Draper, C.A. Ewing, J. Mater. Sci. 19, 38153825 (1984)

17. K.-m. Zhang, J.-x. Zou, J. Li, Z.-s. Yu, H.-p. Wang, Transactions of Nonferrous Metals Society of China, 20, 2192-2197 (2010)

18. X. Zeng, T. Yamaguchi, K. Nishio, Optics and Laser Technology, 80, 84-91 (2016)

19. Y. Lin, J. Yao, Y. Lei, H. Fu, L. Wang, Optics and Lasers in Engineering, 86, 216-227 (2016)

20. Y. Lin, Y. Lei, X. Li, X. Zhi, H. Fu, Optics and Lasers in Engineering, 82, 48-55 (2016)

21. L.L. Bai, J. Li, J.L. Chen, R. Song, J.Z. Shao, C.C. Qu, Optics and Laser Technology, 76, 33-45 (2016)

22. O.G. Lenivtseva, I.A. Bataev, M.G. Golkovskii, A.A. Bataev, V.V. Samoilenko, N.V. Plotnikova, Appl. Surf. Sci. 355, 320-326 (2015)

23. O.G. Lenivtseva, D.V. Lazurenko, V.V. Samoylenko, Applied Mechanics and Materials, 682, 14-20 (2014)

24. O. Lenivtseva, E. Golovin, V. Samoylenko, D. Mul, D. Golovin, 1040, 784-789 (2014)

25. D.O. Mul, E.A. Drobyaz, I.K. Chakin, V.V. Samoylenko, V.S. Lozhkin, R.A. Dostovalov, Obrabotka metallov (tekhnologiya, oborudovanie, instrumenty), 60, 115-120 (2013)

26. J. Cheol Oh, D.-K. Choo, S. Lee, Surf. Coat. Technol. 127, 76-85 (2000)

27. K. Euh, J. Lee, S. Lee, Metall. Mater. Trans. A. 32, 2499-2508 (2001)

28. J.C. Oh, S. Lee, M.G. Golkovski, Metall. Mater. Trans. A. 32, 2995-3005 (2001)

29. I.A. Bataev, A.A. Bataev, M.G. Golkovsky, A.Y. Teplykh, V.G. Burov, S.V. Veselov, Surf. Coat. Tech. 207, 245-253 (2012)

30. I.A. Bataev, A.A. Bataev, M.G. Golkovski, D.S. Krivizhenko, A.A. Losinskaya, O.G. Lenivtseva, Appl. Surf. Sci. 284, 472-481 (2013)

31. Standard Test Method for Measuring Abrasion Using the Dry Sand/Rubber Wheel Apparatus, (ASTM International, 2010) 